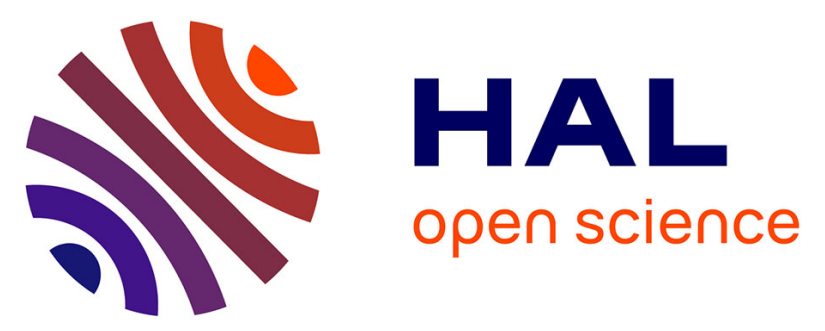

\title{
Adherence to medication is associated with non-planning impulsivity in euthymic bipolar disorder patients
}

Raoul Belzeaux, Laurent Boyer, Pascale Mazzola-Pomietto, Pierre Michel, Nadia Correard, Valerie Aubin, Frank Bellivier, Thierry Bougerol, Emilie Olie, Philippe Courtet, et al.

\section{To cite this version:}

Raoul Belzeaux, Laurent Boyer, Pascale Mazzola-Pomietto, Pierre Michel, Nadia Correard, et al.. Adherence to medication is associated with non-planning impulsivity in euthymic bipolar disorder patients. Journal of Affective Disorders, 2015, 184, pp.60-66. 10.1016/j.jad.2015.05.041 . hal-01985796

\section{HAL Id: hal-01985796 https://hal.science/hal-01985796}

Submitted on 18 Jan 2019

HAL is a multi-disciplinary open access archive for the deposit and dissemination of scientific research documents, whether they are published or not. The documents may come from teaching and research institutions in France or abroad, or from public or private research centers.
L'archive ouverte pluridisciplinaire HAL, est destinée au dépôt et à la diffusion de documents scientifiques de niveau recherche, publiés ou non, émanant des établissements d'enseignement et de recherche français ou étrangers, des laboratoires publics ou privés. 


\title{
Adherence to medication is associated with non-planning impulsivity in euthymic bipolar disorder patients
}

\author{
Raoul Belzeaux ${ }^{a, b, c, n}$, Laurent Boyer ${ }^{d}$, Pascale Mazzola-Pomietto ${ }^{e}$, Pierre Michel ${ }^{d}$, \\ Nadia Correard ${ }^{a, c}$, Valerie Aubin ${ }^{c, f}$, Frank Bellivier ${ }^{\mathrm{c}, \mathrm{g}}$, Thierry Bougerol ${ }^{\mathrm{c}, \mathrm{n}}$, Emilie Olie ${ }^{\mathrm{c}, \mathrm{h}}$, \\ Philippe Courtet ${ }^{\mathrm{c}, \mathrm{h}}$, Bruno Etain ${ }^{\mathrm{c}, \mathrm{m}}$, Sébastien Gard ${ }^{\mathrm{c}, \mathrm{i}}$, Jean-Pierre Kahn ${ }^{\mathrm{c}, \mathrm{j}, \mathrm{k}}$, \\ Christine Passerieux ${ }^{c, l}$, Marion Leboyer ${ }^{c, m}$, Chantal Henry ${ }^{c, m}$, Jean-Michel Azorin ${ }^{a, c, d}$, \\ French Advanced Centers of Expertise for Bipolar Disorders (FACE-BD) Collaborators
}

\footnotetext{
a Pôle de psychiatrie, Hôpital Sainte Marguerite, Assistance Publique Hôpitaux de Marseille, France

${ }^{\mathrm{b}}$ Aix-Marseille Université, CNRS,CRN2M UMR 7286, 13344 cedex 15,Marseille, France

${ }^{\mathrm{c}}$ Fondation FondaMental, Créteil, France

${ }^{d}$ EA 3279-Self-perceived Health Assessment Research Unit,School of Medicine, Timone University, Marseille, France

${ }^{\text {e }}$ Aix-Marseille Université, CNRS,INT UMR 7289, 13385 cedex 15, Marseille, France

${ }^{f}$ Service de psychiatrie, Centre hospitalier Princesse-Grace, Avenue Pasteur,Monaco

${ }^{g}$ AP-HP, GH Saint-Louis-Lariboisière-Fernand Widal, Pôle Neurosciences,Paris, France

${ }^{\mathrm{h}}$ Département d'Urgence et Post Urgence Psychiatrique, CHRU Montpellier, INSERM U1061,Université Montpellier 1, Montpellier, France

' Hôpital Charles Perrens, Centre Expert Trouble Bipolaire, Service de psychiatrie adulte, Pôle 3-4-7, Bordeaux, France

j Service de Psychiatrie et Psychologie Clinique, CHU de Nancy, Hôpitaux de Brabois, Vandoeuvre Les Nancy,France

k Université de Lorraine, France

' Université de Versailles Saint-Quentin, Centre Hospitalier de Versailles, Service de Psychiatrie Adulte, Le Chesnay,France

m Inserm, U955, Equipe de psychiatrie génétique et Université Paris Est, Faculté de médecine et AP-HP,Hôpitaux Universitaires Henri Mondor, Pôle de psychiatrie, Créteil 94000 , France

${ }^{n}$ Clinique Universitaire de Psychiatrie, CHU de Grenoble, Grenoble, France
}

Keywords:

Substance Use Disorders Impulsivity Anxiety disorders Mood disorders

\section{abstract}

Background: Adherence to medication is a major issue in bipolar disorder. defined as a lack of future orientation, has been demonstrated to be the main impulsivity domain altered during euthymia in bipolar disorder patients. It was associated with comorbidities. Methods: To investigate relationship between adherence to medication and non-planning impulsivity, we included 260 euthymic bipolar patients. Adherence to medication was evaluated by Medication Adherence Rating Scale and non-planning impulsivity by Barrat Impulsiveness Scale. Univariate analyses and linear regression were used. We conducted also a path analysis to examine whether non-planning impulsivity had direct or indirect effect on adherence, mediated by comorbidities.

Results: Adherence to medication was correlated with non-planning impulsivity, even after controlling for potential confounding factors in linear regression analysis (Beta standardized coefficient $1 / 40.156$; p $1 / 4$ 0.015). Path analysis demonstrated only a direct effect of non-planning impulsivity on adherence to medication, and none indirect effect via substance use disorders and anxiety disorders.

Limitations: Our study is limited by its cross-sectional design and adherence to medication was assessed only by self-questionnaire.

\footnotetext{
${ }^{n}$ Corresponding author at: Pôle de psychiatrie, Hôpital Sainte Marguerite, Assistance Publique Hôpitaux de Marseille, $\quad$ France. Tel.: p33 491744082 ; fax: p33 491745578. E-mail address: raoul.belzeaux@ap-hm.fr (R. Belzeaux).

${ }^{1}$ List of FACE-BD Collaborators

H. Laouamri

C. Boudebesse, A. Raust

M. Leroux, S. Sportiche

B. Antoniol, K. M'Bailara

F. Molière

N. Viglianèse, L. Lescalier, O. Perret, M.-A. Lodovighi

R. Cohen, O. Wajsbrot-Elgrabli

M. Polosan, S. Garçon

L. Albertini, I.Cussac, E.Beetz

M.C. Hardy-Bayle, N. Kayser
} 


\section{Introduction}

Poor adherence to medication is one of the main challenges in Bipolar Disorder (BD) treatment. About $12-64 \%$ of BD patients are considered as poor or nonadherent whatever the phase of the illness, including symptomatic remission (Leclerc et al., 2013). Poor adherence to medication is viewed as one of the main factor of poor treatment response (Goodwin and Jamison, 2007). It is associated with a wide range of consequences including relapses, recurrences and an increased risk of suicide (Goodwin and Jamison, 2007; Hong et al., 2011).

As a consequence, understanding why patients are not adherent to medication is a crucial issue. Interestingly, adherence to medication would imply complex decision-making processes and imbalance between short- and long-term advantages and consequences of pill-taking. The inability of an individual to weigh up the long-term as opposed to the immediate results of his action could be defined as non-planning impulsivity or "lack of future orientation". Accordingly, a recent meta-analysis indicated that non-planning impulsivity was increased in remitted bipolar patients in comparison to healthy controls (Saddichha and Schuetz, 2014). In addition, non-planning impulsivity has been also correlated with decision making processes, evaluated by the lowa Gambling Task, in euthymic bipolar patients (Christodoulou et al., 2006) as well as in alcohol-dependent subjects (Tomassini et al., 2012). As a consequence, we hypothesize that higher nonplanning impulsivity may have a strong negative effect on adherence to medication in euthymic bipolar patients.

However, it is not clear how non-planning impulsivity could influence adherence to medication. The inability of an individual to weigh up the long-term as opposed to the immediate results of his action may be an important factor of non-adherence to medication. Moreover, both SUD (Etain et al., 2013) and anxiety disorders (Del Carlo et al., 2012) have been associated with higher non-planning impulsivity in euthymic bipolar patients, while these psychiatric comorbidities were also found to strongly influence adherence to medication (Bauer et al., 2005; Leclerc et al., 2013; Lingam and Scott, 2002). These observations suggest that non-planning impulsivity may influence adherence to medication both directly and indirectly by increasing the risk of SUD and anxiety disorders.

So the aim of this study was to investigate the relationship between non-planning impulsivity and adherence to medication in euthymic BD patients, while considering key socio-demographic and clinical confounding factors. Moreover, we aimed to determine whether the relationship between higher impulsivity and lower adherence is mediated by comorbidities (i.e. SUD and anxiety disorders) or if impulsivity and adherence interact directly.

\section{Patients and methods}

\subsection{Study design and population}

We conducted a cross-sectional multicenter study involving the nine French expert centers created under the aegis of the FondaMental Foundation. The data were extracted from the Fondamental Advanced Centers of Expertise in Bipolar Disorders (FACE-BD) database (Henry et al., 2011). We only included the data from subjects who were at the time of the interview: outpatients, between 18 and 75 years old, diagnosed according DSM-IV criteria (APA, 1994), suffering from either a bipolar disorder type I, type II or Not Otherwise Specified (NOS), in symptomatic remission according to the ISBD task force recommendations (Tohen et al., 2009).

The procedure was approved by the ethical review board (CPPlle de France IX, January 18, 2010) and by the committee in charge of the safety of computerized databases (CNIL) (DR-2011-069).

\subsection{Data collection}

A large standardized clinical evaluation with structured clinical interview for DSM-IV (SCID) (First et al., 1996) was used to determine the diagnosis of $\mathrm{BD}$ and characterize the history of disorder (i.e. age of onset, number of past mood episodes, past psychotic symptoms during previous mood episodes, past mixed episodes), comorbid psychiatric conditions (i.e. lifetime anxiety disorders, no, past or current SUD) and sociodemographic factors (age, educational level and marital status).

Standardized evaluations were used to assess symptomatology and functioning. Manic symptoms were assessed with Young Mania Rating Scale (YMRS) (Young et al., 1978), depressive symptoms with Montgomery Åsberg Depression Rating Scale (MADRS) (Montgomery and Asberg, 1979). Functioning was evaluated with Global Assessment of Functioning (GAF). In accordance with the strongest definition of symptomatic remission as proposed by ISBD task force (Tohen et al., 2009), scores on the MADRS and YMRS had to be inferior to 8 . Focusing specifically our analyses on strictly euthymic patients allow controlling the influence of depressive symptoms on adherence to medication (Belzeaux et al., 2013) as well as on the level of impulsivity (Stanford et al., 2009).

Side effects of treatment were evaluated with Patient Rated Inventory of Side Effects (PRISE) (Belzeaux et al., 2013; Bryan et al., 2010; Rush and Asberg, 1999). PRISE is a self-report questionnaire consisting of a 31-item checklist of side effects that allows evaluating both frequency and severity of side effects experienced by the patients over the last 7 days. Side effects are classified by symptom domain (gastrointestinal, heart, skin, nervous system, eyes/ears, genital/urinary, sleep, sexual functioning, and others, including weight gain). Each domain has multiple symptoms that can be endorsed. For each domain, the patient rates whether or not the symptoms are absent $(1 / 40)$, tolerable ( $1 / 41)$ or distressing ( $1 / 42)$.A total score defines a global side effect level by taking into account both the frequency and the severity of all side effects.

Adherence to medication was measured as a continuous variable by the Medication Adherence Rating Scale (MARS) as previously used in BD by a number of authors (Belzeaux et al., 2013; Rosa et al., 2007; Thompson et al., 2000). The MARS is a self-report consisting of $10-y e s /$ no items and with reverse items. A MARS total score is obtained by summing score of each item. This total score has been shown to correlate with likelihood of medication adherence and a total MARS score Z8 has been found to be associated with a high likelihood of medication adherence (Rosa et al., 2007; Thompson et al., 2000).

Non-planning impulsivity was evaluated by one of the three subscores reflecting three factors of the Barrat Impulsiveness Scale (BIS) version 10 (Patton et al., 1995; Stanford et al., 2009). The BIS is the most widely used self-report measure of impulsivity in the literature. The version 10 was used in current study as it is the last 


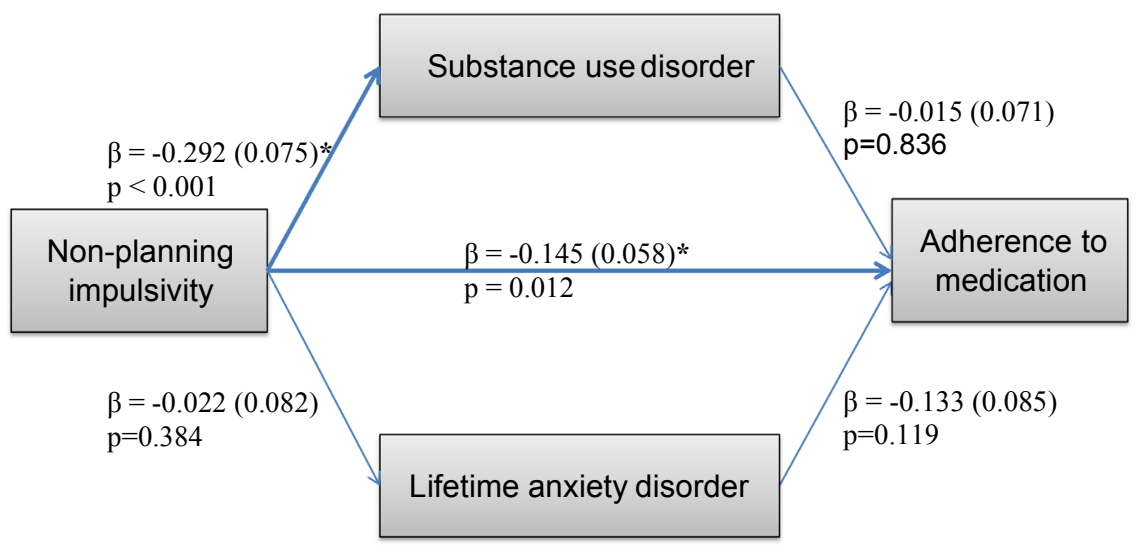

* p-value $<0,05$

RMSEA $=0.064 ; \mathrm{CFI}=0.939 ; \mathrm{WRMR}=0,432$

Coefficients are standardized path coefficients.

Fig. 1. Direct and indirect effect of the non-planning impulsivity on adherence to medication based on path analysis. WRMR $1 / 40.432$, coefficients are standardized path coefficients.

* p-Valueo0.05, RMSEA $1 / 40.064 ; \quad$ CFI $1 / 40.939$

version validated in French language (Bayle et al., 2000) and used in French speaking BD patients (Etain et al., 2013). BIS-10 is a 34item self-report questionnaire that measures impulsiveness as a stable characteristic. Each item is rated on a 4-point scale ranging from 1 (rarely/never) to 4 (almost always/always).

\subsection{Hypothesis and analyses plan}

The main objective of the study was to investigate the relationship between non-planning impulsivity and adherence to medication in remitted euthymic bipolar patients. We first conducted a correlation analysis between MARS total score and the non-planning impulsivity subscores of the BIS-10. Moreover, we explored in univariate analyses other factors associated with adherence.

Then, in order to evaluate whether the correlation between MARS total score and BIS-10 non-planning impulsivity sub-score remained significant when potential confounding factors were taken into account, we performed a linear regression using simultaneous model with several confounding clinical factors that were identified by univariate analyses and examining data from previous studies as covariables.

Finally, we conducted path analysis using maximum likelihood estimation with MPlus. We examined whether the non-planning impulsivity had direct and indirect effects on adherence i.e. if there was a mediated effect of two major comorbidities of BD known to be associated with impulsivity and adherence, namely SUD and anxiety disorders.

\subsection{Data analyses}

Data were expressed as proportions or means and standard deviations. To determine whether univariate normality exists, followed the recommendation of Weston and Gore (2006) examined skewness and kurtosis for each quantitative variable (Weston and Gore, 2006).

As a consequence, the univariate analyses that were used to investigate the associations between MARS score, BIS non-planning impulsivity sub-score and other continuous variables were performed by using nonparametric Spearman's correlations tests. In addition, the analyses testing the effect of gender, familial status, education level, bipolar type and other categorical variables on MARS, were performed by using Mann-Whitney or
Wallis tests as appropriate. Kruskal-Wallis post-hoc analyses were performed when necessary (as described by Marta Garcia Granero, http://gjyp.nl/marta/).

Linear regression was used to control for potential confounding factors. Confounding factors were selected based on the results of univariate analyses with thresholds p-value $\mathrm{r} 0.2$ and data of prior studies. We used as co-factors the following variables: age, illness duration, anxiety disorders, SUD, psychotic features and PRISE total score. We excluded number of previous episodes as it was strongly correlated with illness duration (Spearman's correlation coefficient $1 / 40.427$; po10 ${ }^{5}$ ). Non-normally distributed variables whom distribution deviated from normality (i.e. MARS total score, PRISE total score) were transformed by the mean of a square-root data transformation method as advised by Tabachnick and Fidell (2014) and Howell (2013).

Finally, we conducted a path analysis using weighted least squares estimation with MPlus of the relationships between nonplanning impulsivity, substance use disorder, lifetime anxiety disorder and adherence to medication. We constructed hypothetical relationships among the following variables (i.e., non-planning impulsivity, substance use disorder, lifetime anxiety and adherence to medication) by examining previously published research and results of univariate analyses. We hypothesized that non-planning impulsivity influences adherence, both directly and indirectly via SUD and lifetime anxiety disorders (Fig. 1).

Path analysis is an extension of multiple regression analysis and is a type of structural equation modeling. It assesses the strengths of correlational relationships to clarify potential causal relationships. Coefficients are standardized path coefficients. Path analysis allows one to decompose the sources of a correlation between independent variables (i.e., non-planning impulsivity, substance use disorder, lifetime anxiety disorders) and a dependent variable (i.e., adherence) into direct and indirect effects (Joffe and Mindell, 2006).

Bootstrapping techniques were applied to calculate the $95 \% \mathrm{Cl}$ around the estimates of the direct and indirect effects using 10,000 bootstrap samples.

Model fit was evaluated using the Chi-square test of model fit, the root mean square error of approximation (RMSEA) r0.06, the Comparative Fit Index (CFI) Z0.95, and the weighted root mean square residual (WRMR) o1 (Gamborg et al., 2011).

All statistical tests were two-sided. Significance was defined as pr0.05. Statistical analyses were performed using SPSS Statistics 
Table 1

Sociodemographic and clinical characteristics of 260 euthymic bipolar patients.

\begin{tabular}{|c|c|}
\hline & $\mathrm{n}(\%)$ or mean (SD) \\
\hline \multicolumn{2}{|l|}{ Socio-demographic characteristics } \\
\hline Age (years) & $41.5(712.7)$ \\
\hline Gender (female) & $151(58.1 \%)$ \\
\hline Marital status (single) & $91(35 \%)$ \\
\hline Education level (high school diploma or higher) & $201(77.3 \%)$ \\
\hline \multicolumn{2}{|l|}{ Bipolar disorder type } \\
\hline Bipolar disorder type I & $148(56.9 \%)$ \\
\hline Bipolar disorder type II & $85(32.7 \%)$ \\
\hline Bipolar disorder type NOS & $27(10.4 \%)$ \\
\hline \multicolumn{2}{|l|}{ Comorbidity } \\
\hline Lifetime anxiety disorders & $83(31.9 \%)$ \\
\hline Substance use disorder (SUD) & $66(24.4 \%)$ \\
\hline SUD & $55(21.2 \%)$ \\
\hline SUD & $11(4.2 \%)$ \\
\hline \multicolumn{2}{|l|}{ Symptomatology and functioning } \\
\hline Depressive symptoms (MADRS ${ }^{a}$ ) & $2.8(72.4)$ \\
\hline Manic symptoms (YMRS $\left.{ }^{b}\right)$ & $1.2(71.8)$ \\
\hline Functioning $\left(\mathrm{GAF}^{\mathrm{c}}\right)$ & $73.9(715.9)$ \\
\hline \multicolumn{2}{|l|}{ Impulsivity: BIS ${ }^{d}-10$} \\
\hline BIS-10 nonplanning & $25.5(74.6)$ \\
\hline \multicolumn{2}{|l|}{ Illness course } \\
\hline Illness duration (years) & $15.9(710.7)$ \\
\hline Total number of mood episodes & $8(75.2)$ \\
\hline At least one mood episode with psychotic features & $116(44.6 \%)$ \\
\hline At least one mixed episode & $34(13.1 \%)$ \\
\hline Side effects level (PRISE ${ }^{e}$ ) & $9(77.3)$ \\
\hline Adherence to medication (MARS ${ }^{\mathrm{f}}$ ) & $7.6(71.9)$ \\
\hline
\end{tabular}

${ }^{a}$ Montgomery Åsberg Depression Rating Scale.

${ }^{\mathrm{b}}$ Young Mania Rating Scale.

${ }^{c}$ Global Assessment of Functioning.

${ }^{\mathrm{d}}$ Barrat Impulsivity Scale.

e Patient Rated Inventory of Side Effects.

${ }^{f}$ Medication Adherence Rating Scale.

for Windows, Version 20. Chicago: SPSS Inc.and MPLUS (Muthén and Muthén, 1998-2011).

\section{Results}

\subsection{Population description}

Two hundred and sixty BD patients in symptomatic remission were included in the study. Socio-demographic and clinical characteristics of the sample are summarized in Table 1. Among these patients, $56.9 \%$ had bipolar I disorder and $32.7 \%$ had bipolar II disorder. Mean total scores for MADRS and YMRS were $2.8(72.4)$ and 1.2 ( 71.8) respectively. Mean score for GAF was 73.9 ( 715.9$)$.

In our sample, the mean and median MARS total scores were 7.6 (7 1.9) and 8 (inter-quartile range at 2), respectively. These data indicate sub-optimal adherence behaviors in the whole cohort.

\subsection{Factors associated with adherence to medication}

In the univariate analyses, we found a significant negative correlation between MARS and BIS non-planning sub-score as indicated by Spearman's correlation coefficient $1 / 440.136$ ( $\left.\mathrm{p}^{1 / 1} / 40.029\right)$ (Table 2). Only a significant correlation between MARS total score and duration
Table 2

Sociodemographic and clinical correlates of medication adherence assessed by MARS (total score) in 260 euthymic bipolar patients.

\begin{tabular}{|c|c|c|}
\hline & $\begin{array}{l}\text { MARS }^{a} \text { total } \\
\text { Mean (SD) or } \\
\text { Speaman's correla- } \\
\text { tion coefficient }\end{array}$ & $\begin{array}{l}\text { p-Value (Mann-Withney } \\
\text { test, Kruskal-Wallis test } \\
\text { or Spearman test) }\end{array}$ \\
\hline Age & 0.10 & $\mathrm{p}^{1 / 40.117}$ \\
\hline \multicolumn{3}{|l|}{ Gender } \\
\hline Female & $7.5(2.1)$ & $p^{1 / 40.342}$ \\
\hline Male & $7.8(1.7)$ & \\
\hline \multicolumn{3}{|l|}{ Familial status } \\
\hline Single & $7.3(2.2)$ & $\mathrm{p}^{1 / 40.546}$ \\
\hline Married & $7.6(1.9)$ & \\
\hline Separed & 8.0. (1.4) & \\
\hline \multicolumn{3}{|l|}{ Educational level } \\
\hline $\begin{array}{l}\text { Less than high school } \\
\text { diploma }\end{array}$ & $7.6(2.3)$ & $\mathrm{p}^{1 / 40.312}$ \\
\hline $\begin{array}{l}\text { High school or higher } \\
\text { diploma }\end{array}$ & $7.5(1.9)$ & \\
\hline \multicolumn{3}{|l|}{ Bipolar disorder (BD) Type } \\
\hline BD I & $7.6(2.1)$ & $\mathrm{p}^{1 / 40.558}$ \\
\hline BD II & $7.6(1.8)$ & \\
\hline BD NOS & $7.4(1.7)$ & \\
\hline \multicolumn{3}{|l|}{$\begin{array}{l}\text { At least one mood episode } \\
\text { with psychotic features }\end{array}$} \\
\hline Yes & $7.3(2.2)$ & $\mathrm{p} 1 / 40.107$ \\
\hline No & $7.9(1.5)$ & \\
\hline \multicolumn{3}{|l|}{$\begin{array}{l}\text { At least one past mixed } \\
\text { episode }\end{array}$} \\
\hline Yes & $7.5(1.9)$ & $\mathrm{p}^{1 / 40.227}$ \\
\hline No & $7.8(2.0)$ & \\
\hline Total number of episodes & 0.15 & $\mathrm{p}^{1 / 40.154}$ \\
\hline Illness duration & 0.16 & $\mathrm{p}^{1 / 40.011}$ \\
\hline \multicolumn{3}{|l|}{ Substance use disorder } \\
\hline Current & $6.6(2.4)$ & $\mathrm{p}^{1 / 40.177}$ \\
\hline Past & $7.8(1.8)$ & \\
\hline None & $7.6(1.8)$ & \\
\hline \multicolumn{3}{|l|}{ Lifetime anxiety disorders } \\
\hline Yes & $7.9(1.7)$ & $\mathrm{p}^{1 / 40.154}$ \\
\hline No & $7.5(2.0)$ & \\
\hline PRISE Total score & 0.11 & $\mathrm{p}^{1 / 40.116}$ \\
\hline $\begin{array}{l}\text { BIS- } 10^{\complement} \text { nonplanning } \\
\text { impulsivity sub-score }\end{array}$ & 0.14 & $\mathrm{p}^{1 / 40.029}$ \\
\hline
\end{tabular}

${ }^{\text {a }}$ Medication Adherence Rating Scale.

b Patient Inventory of Side Effects.

${ }^{\mathrm{c}}$ Barrat Implusivity Scale-10.

of the illness was observed (Spearman's coefficient correlati on $1 / 40.160, p^{1 / 4}$ 0.011). No significant linear associations between the level of adherence and sociodemographic variables, clinical variables or PRISE total score were found. A detailed presentation of the data is provided in Table 2.

Based on the results of these univariate analyses, we conducted a linear regression analysis as described in methods section. We found a significant association between MARS total score and BIS10 non-planning impulsivity sub-scale (Beta standardized coefficient $\left.1 \frac{1}{40.156 ;} \mathrm{p} 1 \frac{1}{4} 0.015\right)$, while other factors did not shown significant association (Table 3 ).

\subsection{Path analyses}

Path analysis of the relationships between non-planning impulsivity, substance use disorder, lifetime anxiety disorder and adherence to medication is presented in Fig. 1.

The tested model showed good fit based on the RMSEA $1 / 40.064$, the CFI $1 / 40.939$ and the WRMR $1 / 40.432$.

The path analysis revealed two significant but moderate associations, i.e., the direct effect of non-planning impulsivity on adherence to medication ( $\left.\beta 1 / 40.145, \quad p^{1 / 40.012}\right)$ and the effect of 
Table 3

Factors associated with adherence to medication according to linear regression models using MARS ${ }^{a}$ total score, BIS- $10^{b}$ nonplanning impulsivity sub-scale score, age, illness duration, anxiety disorder, substance use disorder, psychotic features and PRISE total score as co-factors.

\begin{tabular}{|c|c|c|}
\hline & \multicolumn{2}{|c|}{ MARS $^{a}$ Total score ${ }^{d}$} \\
\hline & $\beta^{\mathrm{e}}$ & p-Value \\
\hline BIS- $10^{b}$ nonplanning impulsivity sub-scale score & 0.156 & 0.015 \\
\hline Age & 0.050 & 0.540 \\
\hline Illness duration & 0.148 & 0.061 \\
\hline Lifetime anxiety disorders & 0.083 & 0.178 \\
\hline Substance use disorder & 0.026 & 0.690 \\
\hline Psychotic features & 0.101 & 0.109 \\
\hline PRISE total score ${ }^{e}$ & 0.068 & 0.284 \\
\hline
\end{tabular}

${ }^{\text {a }}$ Medication Adherence Rating Scale.

b Barrat Impulsiveness Scale-10.

${ }^{c}$ Patient Inventory of Side Effects.

d Square Root transformation.

e $\beta$ Standardized coefficient.

non-planning impulsivity on substance use disorder $(\quad \beta 1 / 40.292$, po0.001).

Contrary to our hypotheses, there was no significant indirect effect of non-planning impulsivity on adherence to medication via mediated factors such as substance use disorder or lifetime anxiety disorder (all p-values 4 0.05).

\section{Discussion}

Improving knowledge on factors associated with low adherence to medication is crucial because lower adherence is associated with overall worse prognosis of bipolar disorders. However, non-adherence tends to be under-estimated by psychiatrists and could be hard to predict in clinical practice (De las Cuevas et al., 2013; Lingam and Scott, 2002).

To the best of our knowledge, our study is the first study assessing specifically the hypothesis of a relationship between non-planning impulsivity and low medication adherence in euthymic remitted BD patients. Focusing on patients with symptomatic remission, we evidenced a negative correlation between BIS-10 non-planning impulsivity sub-score and MARS total score. This association remained significant even after controlling for potential confounding factors in a linear regression analysis. Moreover, using path analyses, we demonstrate that the effect of non-planning impulsivity on adherence to medication is not mediated by SUD or anxiety disorders comorbidities but is likely to act directly on adherence.

Our results are consistent with a few previous studies suggesting that non-planning impulsivity influences adherence to medication or treatment dropout. In particular, non-planning impulsivity has been demonstrated to be associated with higher treatment dropout and smoking relapse in smokers (Lopez-Torrecillas et al., 2014). However, in an earlier study carried out in a relative small cohort of patients suffering from different severe psychiatric disorders including BD patients, no significant difference in non-planning impulsivity subscore between patients with or without poor medication adherence was reported (Liraud and Verdoux, 2001). In a larger and recent study, performed in depressed BD type II patients, higher BIS total scores as well as all three domains subscores were demonstrated in non-adherent as compared to adherent patients(Fornaro et al., 2013) but it could not be exclude that mood symptoms influence also impulsivity (Stanford et al., 2009).

Moreover, our results, based on path analysis, suggest that comorbidities, such as SUD, are not causal or intermediate factors on adherence behavior, contrary to the common hypothesis that, in bipolar disorders, SUD may specifically and importantly predispose to lower adherence to medication.

Although our study has a number of strengths (i.e. a large and well characterized sample of bipolar patients in symptomatic remission that includes patients with and without SUD, several level of analyses including path analyses), it also has some limitations. It remains unclear how our findings could be extended to general practice as our sample was recruited from tertiary centers and we focused on patients with symptomatic remission with a good level of functioning, as demonstrated by GAF mean value $1 / 473.9$ ( 715.9$)$. In addition, adherence to medication was assessed only by self-questionnaire. Although the accuracy of such a method that reflects subjective experience of patients is well documented ( Rosa et al., 2007; Thompson et al., 2000), it has been demonstrated that patients' self-report scores tend to overestimate adherence to medication in comparison to serum concentrations (Jonsdottir et al., 2010).

Moreover, based on several previous works, we decided to test specifically the relationship between non-planning impulsivity and adherence to medication. While impulsivity is well known to be a multi-dimensional construct, understanding the relative contribution of each subscale is considered critical (Stanford et al., 2009). Several studies suggested that the different sub-domains of impulsivity may be associated with different biological substrates in genetic (Khadka et al., 2014) as well as electrophysiological studies (Kam et al., 2012). Non-planning impulsivity sub-score was specifically associated with some laboratory measures of impulsivity or cognitive executive functions (Stanford et al., 2009; Swann et al., 2002). Moreover, a comparison of the three subdomains of impulsivity, using BIS, showed the greatest difference between euthymic remitted bipolar patients and healthy controls in non-planning impulsivity compared to the motor and cognitive impulsivity (Saddichha and Schuetz, 2014) suggesting that nonplanning impulsivity is the main impulsivity domain altered during euthymia. Nonetheless, further studies are needed to better characterize the potential importance of other sub-scores of impulsivity in medication adherence behavior.

Finally, our study is limited by its cross-sectional design. Thus we cannot conclude about the cause-effect relationship between high non-planning impulsivity and low adherence.

The results of our study may have several implications for treatment. First of all, they may support the opinion expressed by some authors (Saddichha and Schuetz, 2014) that non-planning impulsivity needs to be taken into account when planning for treatment, as it leads to poor problem solving and low resilience, and to a lack of sense of future. As regards drug treatment, we found only one randomized controlled trial dealing with impulsivity in bipolar disorders, which showed an improvement of nonplanning impulsivity with lithium (Hollander et al., 2005), although there is some evidence for efficacy of other mood stabilizers, antipsychotics and antidepressants on impulsive behavior (Ingenhoven et al., 2010; Singh and Zarate, 2006). Our finding may explain why there are contradictory data regarding better adherence with lithium as compared to other mood stabilizers in bipolar patients (Sajatovic et al., 2007). If indeed lithium does better on non-planning impulsivity, differences in non-planning impulsivity scores among patients included in different studies may be responsible for such findings. Whatsoever, our finding may support the choice of lithium as a first-line treatment in bipolar patients with high scores on non-planning impulsivity, in order to improve adherence to medication.

As far as psychotherapeutic interventions, those that have been shown to be effective on adherence include interpersonal group therapy, cognitive-behavioral therapy, group session for partners of persons with $\mathrm{BD}$, and patient and family psycho-education 
(Sajatovic et al., 2004). However, as highlighted by Moeller et al., one of the most consistently effective treatments currently available for substance dependence involves increasing, through the use of monetary or other types of incentives, short-term rewards for abstinence from substance use. By increasing short-term rewards for abstinence, contingency management therapy targets the lack of non-planning for the future (i.e. impulsivity) that is common in SUD (Moeller et al., 2001). Our findings suggest that this type of intervention could successfully be used to address adherence issues in BD patients, at least in those with high nonplanning impulsivity levels. Interestingly, a recent study (Priebe et al., 2013) reported on the effectiveness of financial incentives to improve adherence to maintenance treatment in bipolar patients.

Finally, cognitive rehabilitation, which was found to display some efficacy to improve executive functioning in bipolar patients (Deckersbach et al., 2010), might enhance adherence in those with non-planning impulsivity. Further studies are warranted to demonstrate the effectiveness of lithium and selected psychotherapeutic interventions in impulsive bipolar patients, as sugg ested by our findings.

In conclusion, our study suggests an association between high non-planning impulsivity and low adherence to medication. demonstrated also that the effect of non-planning impulsivity on adherence to medication is not mediated by the presence of SUD or anxiety disorders.

This result may help to a better understanding of the determinants of non-adherence behaviors. The association between impulsivity and adherence to medication may lead to systematically evaluate impulsivity for example with standardized questionnaire such as BIS in clinical practice to better predict risk of non-adherence and, thus, contribute to promote personalized treatment strategy.

\section{Funding sources}

Authors are members of the FondaMental Foundation as such this work was supported (in part) by the Investissement d'Avenir program managed by the ANR under reference ANR-11- IDEX0004-02.

\section{Conflict of interest}

The authors declare no conflicts of interest.

\section{Acknowledgments}

The authors of this report would like to thank patients with bipolar disorders who agreed to participate in this study and the clinicians, psychologists and nurses who are working in FACE-BD group.

\section{References}

American Psychiatric Association, 1994. Diagnosis and Statistical Manual of Menta Disorders, 4th edition. American Psychiatric Association, Washington, DC.

Bauer, M.S., Altshuler, L., Evans, D.R., Beresford, T., Williford, W.O., Hauger, R., Team, V.A.C.S.2005. Prevalence and distinct correlates of anxiety, substance, and combined comorbidity in a multi-site public sector sample with bipolar disorder. J.Affect. Disord. 85, 301-315.

Bayle, F.J.Bourdel, M.C., Caci, H., Gorwood, P.,Chignon, J.M., Ades, J.,Loo, H., 2000 Factor analysis of french translation of the Barratt impulsivity scale (BIS-10). Can. J.Psychiatry 45, 156-165.

Belzeaux, R., Correard, N., Boyer, L., Etain, B., Loftus, J.,Bellivier, F., Bougerol, T., Courtet, P., Gard, S., Kahn, J.P., Passerieux, C., Leboyer, M., Henry, C., Azorin, J.M. Fondamental Academic Centers of Expertise for Bipolar Disorders, C., 2013. Depressive residual symptoms are associated with lower adherence to medication in bipolar patients without substance use disorder: results from the FACE-BD cohort. J. Affect. Disord. 151, 1009-1015.
Bryan, C., Songer, T., Brooks, M.M., Rush, A.J., Thase, M.E., Gaynes, B., Balasubramani, G.K., Trivedi, M.H., Fava,M., Wisniewski, S.R.,2010. The impact of diabetes on depression treatment outcomes. Gen. Hosp. Psychiatry 32, 33-41.

Christodoulou, T., Lewis, M., Ploubidis, G.B., Frangou, S., 2006. The relationship of impulsivity to response inhibition and decision-making in remitted patients with bipolar disorder. Eur. Psychiatry 21, 270-273.

De las Cuevas, C., Penate, W., Sanz, E.J.,2013. Psychiatric outpatients' self-reported adherence versus psychiatrists' impressions on adherence in affective disorders. Hum. Psychopharmacol. 28, 142-150.

Deckersbach, T., Nierenberg, A.A., Kessler, R., Lund, H.G., Ametrano, R.M., Sachs, G., Rauch, S.L., Dougherty, D., 2010. RESEARCH: cognitive rehabilitation for bipolar disorder: an open trial for employed patients with residual depressive symptoms. CNS Neurosci. Ther. 16, 298-307.

Del Carlo, A., Benvenuti, M., Fornaro, M., Toni, C., Rizzato, S., Swann, A.C.,Dell'Osso, L., Perugi, G., 2012. Different measures of impulsivity in patients with anxiety disorders: a case control study. Psychiatry Res. 197, 231-236.

Etain, B., Mathieu, F., Liquet, S., Raust, A., Cochet, B., Richard, J.R., Gard, S., Zanouy, L. Kahn, J.P.,Cohen, R.F.,Bougerol, T., Henry, C., Leboyer, M., Bellivier, F., 2013. Clinical features associated with trait-impulsiveness in euthymic bipolar disorder patients. J. Affect. Disord. 144, 240-247.

First, Michael, B., Spitzer, Robert, L., Gibbon, Miriam, Williams, Janet, B.W., 1996. Structured Clinical Interview for DSM-IV Axis I Disorders, Clinician Version (SCID-CV). American Psychiatric Press, Inc., Washington, D.C.

Fornaro, M., De Berardis, D., lasevoli, F., Pistorio, M.L., D'Angelo, E., Mungo, S., Martino, M., Ventriglio, A., Cattaneo, C.I., Favaretto, E., Del Debbio, A., Romano, A., Ciampa, G., Elassy, M., Perugi, G., De Pasquale, C., 2013. Treatment adherence towards prescribed medications in bipolar-II acute depressed patients: relationship with cyclothymic temperament and "therapeutic sensation seeking" in response towards subjective intolerance to pain. J. Affect. Disord. 151, 596-604.

Gamborg, M., Jensen, G.B., Sorensen, T.I., Andersen, P.K.,2011. Dynamic path analysis in life-course epidemiology. Am. J. Epidemiol. 173, 1131-1139.

Goodwin, F.K.,Jamison, K.R., 2007. Manic-Depressive Illness. Oxford University Press, New York, pp. 849-868.

Henry, C., Etain, B., Mathieu, F., Raust, A., Vibert, J.F.,Scott, J.,Leboyer, M., 2011. A French network of bipolar expert centres: a model to close the gap between evidence-based medicine and routine practice. J.Affect. Disord. 131, 358-363.

Hollander, E., Pallanti, S., Allen, A., Sood, E., Baldini Rossi, N., 2005. Does sustainedrelease lithium reduce impulsive gambling and affective instability versus placebo in pathological gamblers with bipolar spectrum disorders? Am. J. Psychiatry 162, 137-145.

Hong, J.,Reed, C., Novick, D., Haro, J.M., Aguado, J.,2011. Clinical and economic consequences of medication non-adherence in the treatment of patients with a manic/mixed episode of bipolar disorder: results from the European Mania in Bipolar Longitudinal Evaluation of Medication (EMBLEM) study. Psychiatry Res. 190, 110-114.

Howel, D.C.,2013. Statistical Methods for Psychology. Cengage Learning, Wadsworth.

Ingenhoven, T., Lafay, P., Rinne, T., Passchier, J.,Duivenvoorden, H., 2010. Effectiveness of pharmacotherapy for severe personality disorders: meta-analyses of randomized controlled trials. J.Clin. Psychiatry 71, 14-25.

Joffe, M., Mindell, J.,2006. Complex causal process diagrams for analyzing the health impacts of policy interventions. Am. J. Public Health 96, 473-479. Jonsdottir, H., Opjordsmoen, S.,Birkenaes, A.B., Engh, J.A.,Ringen, P.A., Vaskinn, A., Aamo, T.O.,Friis, S., Andreassen, O.A., 2010. Medication adherence in outpatients with severe mental disorders: relation between self-reports and serum level. J.Clin. Psychopharmacol. 30, 169-175.

Kam, J.W., Dominelli, R., Carlson, S.R., 2012. Differential relationships between subtraits of BIS-11 impulsivity and executive processes: an ERP study. Int. J.Psychophysiol. 85, 174-187.

Khadka, S., Narayanan, B., Meda, S.A., Gelernter, J.,Han, S., Sawyer, B., Aslanzadeh, F., Stevens, M.C., Hawkins, K.A., Anticevic, A., Potenza, M.N., Pearlson, G.D., 2014 Genetic association of impulsivity in young adults: a multivariate study. Transl. Psychiatry 4, e451.

Leclerc, E., Mansur, R.B., Brietzke, E., 2013. Determinants of adherence to treatment in bipolar disorder: a comprehensive review. J.Affect. Disord. 149, 247-252.

Lingam, R., Scott, J.,2002. Treatment non-adherence in affective disorders. Acta Psychiatr. Scand. 105, 164-172.

Liraud, F., Verdoux, H., 2001. Association between temperamental characteristics and medication adherence in subjects presenting with psychotic or mood disorders. Psychiatry Res. 102, 91-95.

Lopez-Torrecillas, F., Nieto-Ruiz, A., Velasco-Ortuno, S., Lara-Fernandez, M., LopezQuirantes, E.M., Castillo-Fernandez, E., 2014. The role of impulsivity in dropout from treatment for cigarette smoking. Compr. Psychiatry 55, 1609-1613.

Moeller, F.G., Dougherty, D.M., Barratt, E.S., Schmitz, J.M., Swann, A.C., Grabowski, J., 2001. The impact of impulsivity on cocaine use and retention in treatment. J. Subst. Abuse Treat. 21, 193-198.

Montgomery, S.A., Asberg, M., 1979. A new depression scale designed to be sensitive to change. Br. J.Psychiatry 134, 382-389.

Muthén, L.K., Muthén, B.O., 1998\&;2011. Mplus User's Guide, sixth ed. Muthén \& Muthén, Los Angeles.

Patton, J.H.,Stanford, M.S., Barratt, E.S.,1995. Factor structure of the Barratt impulsiveness scale. J. Clin. Psychol. 51, 768-774.

Priebe, S., Yeeles, K., Bremner, S., Lauber, C., Eldridge, S., Ashby, D., David, A.S., O'Connell, N., Forrest, A., Burns, T., 2013. Effectiveness of financial incentives to improve adherence to maintenance treatment with antipsychotics: cluster randomised controlled trial. $\mathrm{BMJ} 347, \mathrm{f} 5847$. 
Rosa, A.R., Marco, M., Fachel, J.M., Kapczinski, F., Stein, A.T., Barros, H.M., 2007. Correlation between drug treatment adherence and lithium treatment attitudes and knowledge by bipolar patients. Prog. Neuropsychopharmacol. Biol. Psychiatry 31, 217-224.

Rush, A.J.,Asberg, M., 1999. Patient Rated Inventory of Side Effects (PRISE). Unpublished rating scale. University of Texas, University of Texas Southwestern Medical Center, Dallas.

Saddichha, S., Schuetz, C., 2014. Is impulsivity in remitted bipolar disorder a stable trait? A meta-analytic review. Compr. Psychiatry 55, 1479-1484.

Sajatovic, M., Davies, M., Hrouda, D.R., 2004. Enhancement of treatment adherence among patients with bipolar disorder. Psychiatr. Serv. 55, 264-269.

Sajatovic, M., Valenstein, M., Blow, F., Ganoczy, D., Ignacio, R., 2007. Treatment adherence with lithium and anticonvulsant medications among patients with bipolar disorder. Psychiatr. Serv. 58, 855-863.

Singh, J.B.,Zarate Jr., C.A., 2006. Pharmacological treatment of psychiatric comorbidity in bipolar disorder: a review of controlled trials.

Bipolar Disord. 8 696-709.

Stanford, M.S., Mathias, C.W., Dougherty, D.M., Lake, S.L.,Anderson, N.E., Patton, J. $\mathrm{H}$., 2009. Fifty years of the Barratt Impulsiveness Scale: an update and review. Personal. Individ. Differ. 47, 385-395.

Swann, A.C., Bjork, J.M., Moeller, F.G.,Dougherty, D.M., 2002. Two models of impulsivity: relationship to personality traits and psychopathology. Biol. Psy-
Tabachnick, B.G.,Fidell, L.S.,2014. A practical approach to using multivariate analyses, sixth ed. Pearson Education Limited, Needham Heights.

Thompson, K., Kulkarni, J.,Sergejew, A.A., 2000. Reliability and validity of a new Medication Adherence Rating Scale (MARS) for the psychoses. Schizophr. Res. 42, 241-247.

Tohen, M., Frank, E., Bowden, C.L., Colom, F., Ghaemi, S.N., Yatham, L.N.,Malhi, G.S., Calabrese, J.R.,Nolen, W.A., Vieta, E., Kapczinski, F., Goodwin, G.M., Suppes, T., Sachs, G.S., Chengappa, K.R., Grunze, H., Mitchell, P.B., Kanba, S., Berk, M., 2009 The International Society for Bipolar Disorders (ISBD) Task Force report on the nomenclature of course and outcome in bipolar disorders. Bipolar Disord. 11, 453-473.

Tomassini, A., Struglia, F., Spaziani, D., Pacifico, R., Stratta, P., Rossi, A., 2012. Decision making, impulsivity, and personality traits in alcohol-dependent subjects. Am. J. Addict. 21, 263-267.

Weston, R., Gore, P.A.,2006. A brief guide to structural equation modeling. Psychol. 34, 719-751.

Young, R.C.,Biggs, J.T.,Ziegler, V.E., Meyer, D.A., 1978. A rating scale for mania: reliability, validity and sensitivity. Br. J.Psychiatry 133, 429-435. chiatry 51, 988-994. 